4th International Scientific Conference SEC-IASR 2019, Galati, Romania, 7th - 8th June, 2019

\title{
Intellectual Development and Learning at Early Age. A Theoretical Perspective
}

\author{
Valerica ANGHELACHE \\ https://doi.org/10.18662/lumproc/sec-iasr2019/02
}

How to cite: Anghelache, V. (2020). Intellectual Development and Learning at Early Age. A Theoretical Perspective. In S. Marin \& P. Moisescu (vol. eds.), Lumen Proceedings: Vol. 12. 4th International Scientific Conference SEC-IASR 2019 (pp. 10-19). Iasi, Romania: LUMEN Publishing House.

https://doi.org/10.18662/lumproc/sec-iasr2019/02 


\title{
Intellectual Development and Learning at Early Age. A Theoretical Perspective
}

\author{
Valerica ANGHELACHE ${ }^{1}$
}

Abstract

The intellectual development at early agesoccupies large spaces in the specialized literature. However, there are many issues that have remained unknown or insufficiently explained. In this sense, the present paper aims to illustrate the relation between the characteristics of the child's intellectual development and the learning process at early ages. It is about a theoretical approach by which we have tried to argue the necessity of knowing these particularities of the child's development, as well as the imperative necessity to reconsider the formal learning process. The analysis of the experimental research in the field indicates the existence of clear correlations between the changes that take place at this stage in the architecture of the intellectual development and variables such as: the previous experiences the child had to face with, the quality of the socio-family environment, the parents' educational level, the way the child plays, the degree of leadership of the game-based activities.Moreover, by its content, the paper aims to draw attention upon the importance and complexity of this issue and can be considered a good starting point for the experimental investigation of the changes taking place at the age of intellectual development.

Keywords: intellectual development; cognitive mechanisms; early education; education; learning.

\footnotetext{
1 "Dunărea de Jos" University, Teacher Training Department, Galaţi, Romania, valiang@yahoo.fr
} 


\section{Introduction}

The changes at educational level have undergone major fluctuations along the time, with different consequences in the field of teaching activity and not only. From carefully planned reforms to hasty decisions, all of them have influenced the coherence of the education process. The core of all actions of education renewing was the optimization of the learning activity, facilitating the access to an educational process that intends to be qualitative and that places the student at the centre of its priorities. The repositioning of the instructional-educational approach from teacher to pupil required a reassessment of the educational policies, with structural and praxiological effects at all levels. Gradually it was realized that the student should be considered as a whole and the focus of the didactic approach on its development possibilities and needs should start from kindergarten.

Initially bypassed by changes in essence, early childhood education has been invested with due importance in the last 15-20 years, today being approached from a broader perspective, that of early education. The premise from which it started is that learning at a early age - as a formative and systematic approach - can increase the chances of a future optimal learning. The current educational policies regarding early education aim to capitalize certain European practices in the field, reconsidering the role and importance of early education in general and preschool in particular, in the process of training and child development. This aspect entails reconsidering the specificity of the learning process at preschool age and, implicitly, the reassessment of the educational purposes at this stage.

The analysis of the particularities of intellectual development, of the cognitive mechanisms of the child at a early age becomes a necessity in the current context. Questions such as how or whatdoes the child learn at this age are constantly in the mind of the educator, called to design and develop a didactic approach with training and instructional values that are consistent with the child's level of intellectual development. However, the mere questioning on this aspect is not sufficient. It is necessary to identify methodological tools, strategies to ensure the child's access to knowledge, to facilitate the understanding of the surrounding world and the causal relations, in accordance with the particularities of intellectual development at this age.

The processionality of learning at early ages, its quality is multiply determined: on one hand, by the particularities of intellectual development, by the flexibility and mobility of the cognitive structures of the child at this age, on the other hand, on certain volitional and affective-attitudinal features.From this perspective, the design of the curriculum for early ages 
must logically and objectively relate to what the child can assimilate and experience at this stage.

\section{Theoretical Background}

The modality of learning structuring, as well as the particularities of the intellect development, occupy ample spaces in the specialized literature. Neurophysiologists, psychologists and pedagogues are constantly trying to go into the complexity of these processes, testing hypotheses, identifying models for interpreting the mechanisms that support and regulate intellectual development, trying to explain either some generally valid aspects or traits related to the individualization of this process.In the following paragraphs, we are to detail some aspects regarding the mechanisms of intellectual development and learning at early ages, reflected by certain researches in the field.

The quality of the cognitive mechanisms at early ages - in this case referring to the mechanisms of secondary information processing - is directly dependent on the level of intellectual development, an aspect supported by Piaget, from the point of view of the results of a systematic observation process of his own children. We owe to him the stage of the intelligence development process, each of these stages illustrating a certain balance of the individual's actions, related to the environmental challenges. The transition to a higher stage represents the result of an imbalance in the relation with the environmental challenges and it is achieved by mobilizing the regulatory processes. In fact, Piaget considers (1973) that it is about the processes of adaptation and adjustment. „Intelligence is an adaptation. In order to notice its relations with life in general, we must specify what relations exist between the organism and the environment"[8].Besides, Zlate argues that (1999), "the cognitive structures, depending on a number of factors (the nature and quantity of processed information, the general and particular significance of this information for the individual, the essential or non-essential, empirical or scientific character of the information, etc.), produce adaptive or non-adaptive effects on the rational behaviors of the individual'"[14].

Between 2-7 years, the child is in the preoperative thinking stage, going through two distinct sub-stages: the preconceptional thinking stage (2-4 years) and the intuitive thinking stage (4-7 years) [7].Pre-conceptual thinking is marked by the formation of representations, language acquisition and internalization of previously assimilated motor schemes. We are not talking about the use of concepts at this time. The intuitive thinking marks the 
emergence of symbolic thinking, the use of language as a tool for optimizing children's actions and focusing on the real.From the perspective of thinking development, the two sub-stages illustrate what Scarr and Vander Zanden (1987, cited by Zlate, 1999) call non-directional (non-directive) and directed (deliberate) thinking [14]. The stage of preoperative intelligence marks the shift from non-directional thinking, which uses images, to directive thinking, guided by purpose.

Memory, as a psychological mechanism for engraming, storing and updating information, has distinct qualities at early age, being closely linked to thinking, language and attention. The success of learning at this stage of development is directly dependent on the efficiency of memory, is based on it and exploits the quality of the mnesic processes. For preschoolers, for example, the efficiency of memory processes increases. The child makes the step from involuntary to voluntary memory, considering that the sphere of knowledge and the meanings it acquires, increases. Generally, the child retains and updates concrete experiences and information that he or she manages to use logically and which have affective resonance. Compared to the first two years of life, at this age the explicit memory operates, the semantic one (responsible for understanding the way things work and storing knowledge). However, Zlate argues, the preschooler's memory is "undifferentiated, diffuse, incoherent, non-systematic, chaotic" [14].

Language, as a cognitive mechanism, is closely related to the development of explicit memory and thought. Moreover, Vîgotsky (1985) considers that language is the basis of thought, organizing it, thus being situated in a position diametrically opposed to Piaget [13]. At early age, the oral, written and readable language develop. Regarding imagination, at early ages it is particularly present in the child's play. The possible and the impossible, the real and the fantastic animate the child's existence.

Starting from these aspects related to the intellectual development of the child at early age, the paper aims to highlight the concrete way in which the particularities of intellectual development are reflected and influence the acquisition of elementary competences of the child. We also intend to clarify some aspects related to the instructional-educational approach made by the didactic framework, by reference to the specificity of the cognitive mechanisms that the child can use at early ages.

\section{Argument of the paper}

Early childhood education is the result of a multitude of influences coming from both the family and the kindergarten. In our opinion, the 
educational potential of these influences is dependent on several essential factors:

- The quality of the family environment. Seen as a social microuniverse, the family can provide the child with opportunities of understanding the relations with others, of learning norms with moral values, opportunities of experiencing the daily life.

- The cultural and educational level of the family, which will facilitate (or not) the construction of the child's aperceptiv fund.

- The quality of the informative and formative approach offered by the kindergarten, more precisely the type and the quality of the experiences to which the child has access in the learning activities.

In our opinion, the reconsideration of the learning process at early age, as a formal educational approach, is based on several solid arguments:

a) Provides access to the understanding of the surrounding world.The range of learning activities offered by the kindergarten facilitates the child's internalization of the mechanisms of adaptation to the real, helps him/ her in the process of constructing mental operations and structuring the intelligence. In fact, the learning outcomes at this age reflect the child's ability to understand certain causal relations between phenomena, objects or persons.

b) Shapes the acquisitions at socio-affective and motric level.The didactic process in the kindergarten develops the register and the quality of the child's interactions with the children of the same age, but also with adults (other than those in the family). ). The child learns to adapt to others, to control their emotions, to socialize. Moreover, the child develops at a physical level, with emphasis on the development of sensory-motor, fine and rough motricity.

c) It lays the foundations of organized, systematic and continuous learning. The child's entry in the kindergarten makes him get used to observing a daily activity programme, with some rules related to the cooperation with the others, with the participation in different learning activities of a playful character which develop his/ her thinking, shapes his/ her will and attention, enhances his/ her imagination.

d) Ensures the premises for obtaining school-type acquisitions. The formal approach to learning requires designing activities and learning experiences with a high degree of attractiveness for the child, as well as using of content that stimulates his/ her interest in learning, creates a state of expectation, cultivates his/ her initiative, to stimulate his/ her creativity. 


\section{Arguments to support the thesis}

The arguments given above are equally supported by our own investigations, both experimental and based on a systematic observational approach, but also by numerous other research in the field. We will refer to some of these in the following paragraphs.

The importance of the educational and cultural history of the family in the process of child development is supported by the research conducted by Soheir et al. (2017).Using standardized investigations tools, the research authors intended to evaluate a sample of 510 subjects (preschoolers between the ages of 24 and 60 months) in terms of intellectual development, as well as other components of children's development (communication and problem solving, socializing skills, fine and rough motricity). The study has also taken into account the following variables: prenatal, natal, postnatal, family, developmental history, results of a complete clinical examination, IQ, measured using the Stanford-Binet test. For 15 subjects, the research results indicated a prevalence of developmental delay. These children experienced learning difficulties and language disorders, which are present in the family history as well. Risk factors for intellectual development were also reported in the case of children from families with a low educational level.Besides, a positive correlation was identified between the higher level of parent education and motor skills (fine motricity) and problem solving skills [11].The results of this investigation are in agreement with similar results obtained by Bulgarelli and Molina (2016). They investigated the role of the type of care and the family's educational level in the development of social cognition and the ability to understand emotions at early age. The results obtained illustrate strong correlations between the mother's educational level and the child's development level [2]. A possible explanation may also be that mothers are aware of the importance of spending quality time with their children.

The quasi-experimental research conducted by Phillips-Silver and Daza (2018) on a small sample of preschoolers of 3 years old tried to demonstrate the importance of the kindergarten training approach in terms of cognitive flexibility and inhibitory control. The results lead to the conclusion that an educational curriculum adapted to the needs and particularities of the development of preschool children can feed and support an optimal level of intellectual development [9].The fact that the design model and the quality of the didactic approach offered by the kindergarten largely influence the child's capacity development is supported by an experimental research conducted by us in 2012, on a sample of 240 preschoolers aged 5 years. The results showed that the integrated teaching of 
knowledge played a major role in the intellectual and motor development of children (development of logical-mathematical thinking, language, motor skills, creativity, development of comprehension of the surrounding world)[1].

The relation between previous experiences and the child's development can also be argued from the perspective of neurologists' research. Analyzing the factors responsible for cortical plasticity throughout life, neuroscience specialists believe that the events and experiences acquired at early ages have the power to influence brain architecture and behavioral development.Fox, Levitt and Nelson (2010) argue that "learning at early age lays the foundation for further learning and is essential (though not sufficient) for optimal brain architecture development"[4].Moreover, if we refer to the relation experience - cognitive development, we should analyze the benefits of the experiences gained from the activity directed by the teacher and the experiences gained through free activities, not oriented towards a purpose.Thus, Early (2010) argues that the time spent by the child in kindergarten, but without being involved in an activity, as well as free, non-oriented play, have extremely small effects on the child's cognitive development [3]. Furthermore, Lillard et al. (2013) consider that the unstructured play or the activities selected exclusively by the child do not help him/ her have a cognitive progress, even if these activities aim at creativity or problem solving through cooperation [6]. Similar are the results of the investigations of Fuller et al. (2017), which show that a longer time allocated to activities with academic content (for example, the acquisition of communication skills, mathematical skills) has greater effects on the early learning process [5].

The relation between learning at early age and school learning also finds support in the investigations conducted by Sylva (1994). The results obtained from the analysis of the effects on the development of the child produced by preschool education, curriculum, typology of the cognitions, of motivation, of relating to success and performance, emphasize the following aspects:

- the child's participation in very well-conceived, cognitively oriented preschool programmes was associated with subsequent school competence;

- an effective preschool curriculum should not be limited to instilling a few simple cognitive behaviours or skills;

- the child orientation towards learning purposes favours a way of thinking that can support the students' involvement in learning [12]. 
Detailing some of the research results that support our arguments regarding the relation between the child's early learning and intellectual development should not be understood as an exclusive plea for the academic orientation of activities and experiences at this age, for promoting directism over independent activity, for academic learning to the detriment of the play.After all, at early age, the child's acquisitions, including those on the cognitive level, occur through involvement in activities of a playful nature, which have an affective resonance for the child, which satisfy his/ her need for fantastic and miraculous, the need to "master the world" through incredible powers.Moreover, Scharer (2017) considers that, in order to determine the child's development, the game itself must be developed. After learning different types of games, towards the end of preschool age, the child becomes more and more interested in learning activities, those of school type, which involve systematic and continuous effort, the awareness of effort necessity and which valorizes at a higher level thinking the memory qualities and attention [10]. The play develops the child's ability to selfregulate, favoures cognitive decentralization, develops motivation and the ability to set goals. At early age, play and learning do not represent separate activities.

\section{Conclusions}

Approaching a coherent learning process at early ages requires relating to the psychology of human development.It analyzes the changes that take place physically, cognitively and psycho-socially, as well as their particularities at different stages of life. In this sense, we can talk about several defining features: general features, valid for all individuals, but also about features that personalize, individualize the process of change. It is already known that, against the background of age features, wich are generally valid, some individual features are distinguished in terms of child development and learning.Moreover, intellectual development is determined biologically, but also by the socio-cultural context.The quality of the experiences, the way of structuring the cognitions, the type of care, the particularities of the environment, the way in which each child internalizes the external events and challenges, make the intellectual development gain distinct accents, favouring either normal or deficient development. From this point of view, the training process at early ages must be in accordance with the general and individual particularities of intellectual development at this age. In this regard, we consider some recommendations to be necessary: 
- training teachers from the perspective of understanding the particularities of the early ages in terms of intellectual development and how the child responds to learning requirements in a formal framework;

- optimal use of the child's previous experiences, of the pre-knowledge system which the child integrates into kindergarten activities with;

- building on non-formal learning activities that may have training and instructional values at least as important as formal ones;

- designing learning activities that offer the child a consistent intuitive support;

- the adult's involvement in the child's play, with the purpose of orienting him/ her towards a goal, of offering him new perspectives for understanding the action;

- using knowledge that is formative and explanatory, plausible in relation to everyday life and also attractive in order to stimulate the child's thinking and motivation;

- objective assessment of the child's progress, according to his/ her real development possibilities;

- designing recovery programs, in the case of children who are susceptible to deficient development at cognitive, motor or relational level.

Connecting formal learning to the imperatives and specificity of intellectual development at early ages (and beyond) is a keen necessity. This involves the recalibration of the educational curriculum, the investigation of new clues regarding the satisfaction of the child's needs according to the specificity of the intellectual development at this stage.

\section{References}

[1] Anghelache V, Bentea CC. Integrated teaching - the new curricular design of pre-primary educational system in Romania. Procedia - Social and Behavioral Sciences. 2012; 51:125-129.

[2] Bulgarelli D, Molina P. Social Cognition in Preschoolers: Effects of Early Experience and Individual Differences. 2016; Front. Psychol. 7:1762.

[3] Early D, Iruka I, Ritchie S, Barbarin O, Winn D. et al. How do prekindergarteners spend their time? Gender, ethnicity, and income as 
predictors of experiences in pre-kindergarten classrooms. Early Child Research Quarterly. 2010; 25:177-193.

[4] Fox SE, Levitt P, Nelson CA. How the timing and quality of early experiences influence the development of brain architecture. Child Development. 2010; 81(1):28-40.

[5] Fuller B, Bein E, Bridges M, Kim Y, Rabe-Hesketh S. Do academic preschools yield stronger benefits? Cognitive emphasis, dosage, and early learning. Journal of Applied Developmental Psychology. 2017; 50:1-11.

[6] Lillard AS, Lerner MD, Hopkins EJ, Dore RA, Smith ED, Palmquist CM. The impact of pretend play on children's development: A review of the evidence. Psychological Bulletin. 2013, 139(1):1-34. Available from: https://psycnet.apa.org/doiLanding?doi=10.1037\%2Fa0029321.

[7] Piaget J. Psihologia inteligenței [The psychology of intelligence]. Bucureşti: Editura Ştiințifică; 1965.169.

[8] Piaget J.Naşterea inteligenței la copil [The birth of intelligence to the child]. Bucureşti: Editura Didactică şi Pedagogică; 1973. 11.

[9] Phillips-Silver J, Daza MT. Cognitive Control at Age 3: Evaluating Executive Functions in an Equitable Montessori Preschool. Front. Educ. 2018; 3:106.

Available

from:https://www.frontiersin.org/articles/10.3389/feduc.2018.00106/full.

[10] Scharer JH. Supporting Young Children's Learning in a Dramatic Play Environment. Journal of Childhood Studies. 2017; 42(3): 66-69. Available from: https://journals.uvic.ca/index.php/jcs/article/view/17895.

[11] Soheir SA, Tawfik MAM, Barseem NF, Elatabany AMM. Assessment of intellectual development in preschool children in the East of Menoufia Governorate, Egypt. Menoufia Medical Journal. 2017; 30:741-747.

[12] Sylva K. School Influences on Children's Development. Journal of Child Psychology and Psychiatry. 1994; 35(1):135-170.

[13] Vîgotski L.S. Pensée et language. Paris: Editions Sociales; 1985.

[14] Zlate M. Psihologia mecanismelor cognitive [Psychology of cognitive mechanisms]. Iaşi: Editura Polirom; 1999. 267 p. 